\title{
Using Movies to Teach Music Business
}

\author{
Clyde Philip Rolston \\ Belmont University \\ This paper was presented at the 2019 International Summit of the \\ Music \& Entertainment Industry Educators Association
}

March 21-23, 2019

\section{https://doi.org/10.25101/19.37}

\section{Abstract}

For the last four years I have taught an elective course in Music Business that uses feature and documentary films. The course has been offered as a standalone music business elective and a course linked with a general education humanities class. Specific scenes are used as case studies on artist management, record label contracts, touring, live show productions, career paths, and other topics. Common themes of artist careers are explored as is how Hollywood portrays the industry in film. Special attention is given to how the movie industry portrays the music industry, artists, and their stories, verses the reality of those stories. In this presentation I will share how faculty can create similar courses or use film in existing courses. Topics may include:

- Course structure to maximize the student's understanding of the industry

- Choosing the right films

- Making films available to students

- Technical issues related to class presentations

- Finding appropriate related readings

- Hidden course fees

- Assessing student learning, including paper topics and grading rubrics

Keywords: music business education, music business pedagogy, general education, music industry case studies
Clyde Philip Rolston is Professor of Music Business in the Mike Curb College of Entertainment and Music Business at Belmont University and co-author of Record Label Marketing: How Music Companies Brand and Market Artists in the Digital Era, 3rd edition. Prior to joining the faculty at Belmont University he was a Vice President of Marketing at Centaur Records, Inc. where he engineered and produced many projects, including recordings by the Philadelphia Trio and the London Symphony Orchestra. He is an active member of the Music and Entertainment Industry Educators Association. Dr. Rolston received a Ph.D. in Marketing from Temple University and has taught marketing to music business students for over twenty years.

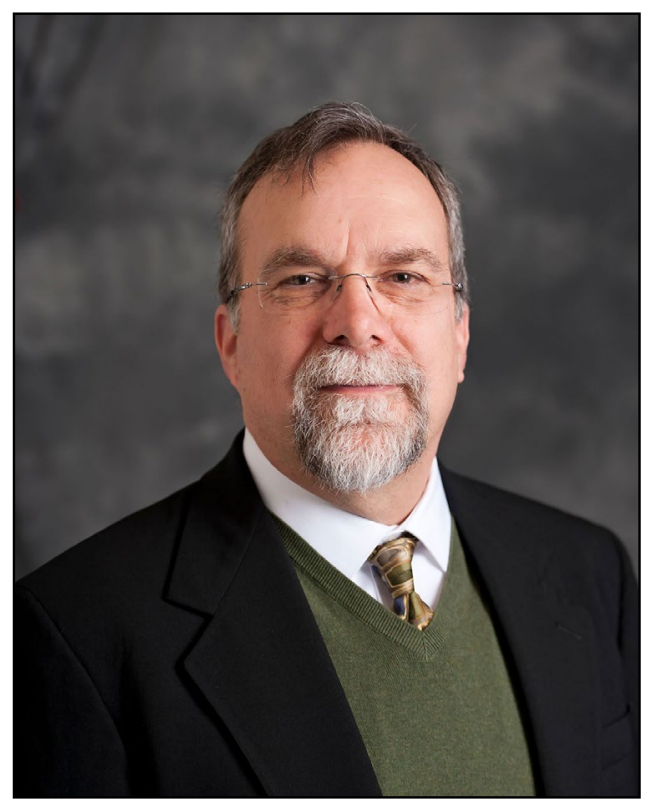




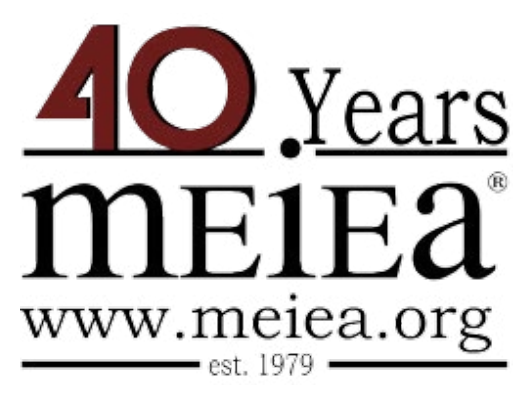

\section{PROCEEDINGS OF THE \\ 2019 INTERNATIONAL SUMMIT \\ OF THE \\ MUSIC \& ENTERTAINMENT \\ INDUSTRY EDUCATORS \\ ASSOCIATION}

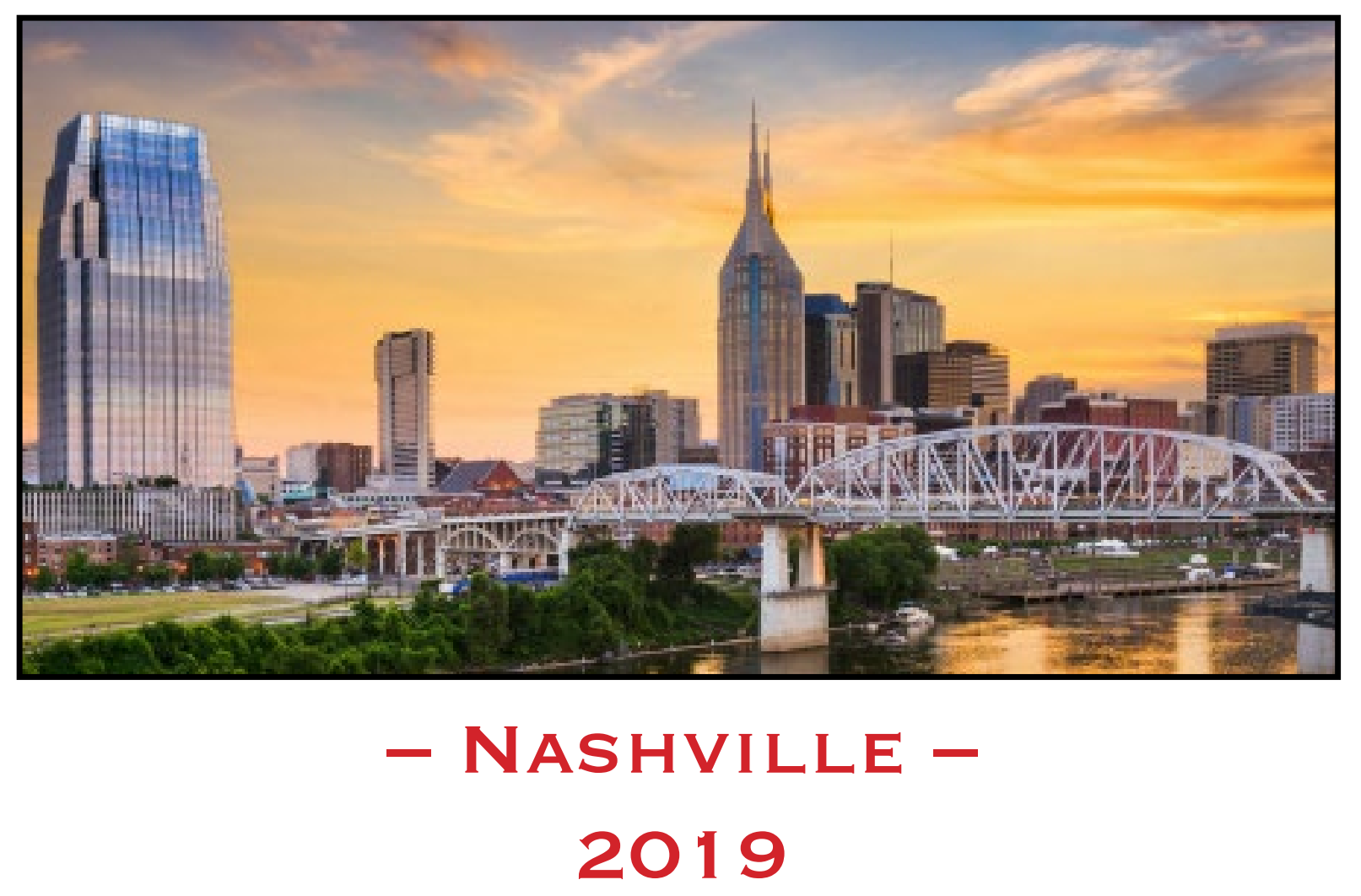

March 21 - 23, $2019 \cdot$ Belmont University - Nashville 